\title{
THERMAL VACUUM TESTING OF SWIFT XRT ETHANE HEAT PIPES
}

\author{
Mark Kobel \\ Jentung $\mathrm{Ku}$ \\ NASA Goddard Space Flight Center \\ Greenbelt, MD 20771 \\ (301) 286-8832 \\ Mark.C.Kobel@nasa.gov
}

\begin{abstract}
This paper presents the results obtained from a recent ethane heat pipe program. Three identical ethane heat pipes were tested individually, and then two selected heat pipes were tested collectively in their system configuration. Heat transport, thermal conductance, and non-condensable gas tests were performed on each heat pipe. To gain insight into the reflux operation as seen at spacecraft level ground testing, the test fixture was oriented in a vertical configuration. The system level test included a computer-controlled heater designed to emulate the heat load generated at the thermoelectric cooler interface. The system performance was successfully characterized for a wide range of environmental conditions while staying within the operating limits.
\end{abstract}

\section{INTRODUCTION}

The X-Ray Telescope (XRT) instrument on the Swift spacecraft required ethane as the heat pipe working fluid to satisfy the operating temperature requirement of $-40 \mathrm{C}$ to $-105 \mathrm{C}^{1}$. The Focal Plane Camera Assembly (FPCA) utilizes a charged couple detector (CCD) camera which is temperature controlled by a thermoelectric cooler (TEC). The heat pipes are required to cool the hot side of the (TEC) through an interface. A pair of heat pipes was chosen for redundancy and each heat pipe is capable of carrying the total load in the event of a secondary heat pipe failure. Each individual heat pipe characterization was performed using dedicated aluminum heater block at the evaporator end and a common temperature controlled cold plate at the condenser end.

Two of the heat pipes were integrated with the radiator to form the heat rejection system (HRS). The HRS test requires a heat transport of 10 watts while maintaining the evaporators at or below $-40 \mathrm{C}$ for the hot case environmental conditions. Orbital temperatures profiles were implemented for the radiator sink target to fully characterize the operation of the HRS. There has been limited publications regarding the use of ethane heat pipes in the past ${ }^{2}$.

\section{TEST ARTICLES}

\section{Constant Conductance Heat Pipes}

Three identical ethane Constant Conductance Heat Pipe's (CCHP's) were tested in this program. The heat pipe was made of an aluminum extrusion with twenty trapezoidal axial grooves. The inner diameter, outer diameter and length of the heat pipe were $9.854 \mathrm{~mm}$, $11.074 \mathrm{~mm}$, and $0.658 \mathrm{~mm}(0.384 \mathrm{in.}, 0.436 \mathrm{in}$. and $0.0259 \mathrm{in}$.), respectively. Each heat pipe was $2,337 \mathrm{~mm}$ (92 in.) in linear length and has contains three 90 degree bends in a two dimensional plane, forming a "W" shape. The evaporator section was $254 \mathrm{~mm}$ (10 in.) in length and the condenser section was $400 \mathrm{~mm}$ (15.75 in.) in length. This leaves a $1,683 \mathrm{~mm}(66.25 \mathrm{in}$.) adiabatic section. The flange width was $34.823 \mathrm{~mm}$ (1.371 in.) and was $1.5875 \mathrm{~mm}(0.0625 \mathrm{in}$.) thick. All flanges were machined off the transport section of the CCHP, except at two locations where the flanges were left intact (for mounting flexures) to minimize any structural loads imparted to the FPCA. Nut plates were permanently mounted to the condenser flanges with EA9394 epoxy. Each CCHP weighs roughly 350 grams (including ethane charge, but not the nut plates) and was charged with 33 grams of high purity ethane. Each pipe was designed to carry 10 watts of power nominally at an operating temperature of $-40^{\circ} \mathrm{C}$.

\section{Heat Rejection System}

The Heat Rejection System (HRS) consists of two heat pipes mounted to a common interface plate, radiator, mounting brackets and multi layer insulation (MLI). The condensers were mounted to the flight radiator having a direct view of a temperature controlled sink plate. The HRS was mated to the FPCA mass model casing, cold finger/proton shield thermal simulator assembly. The FPCA simulator assembly was designed to reproduce the thermal load presented to the heat pipe evaporators and simulate the thermal characteristics of the FPCA itself.

\section{TEST SET-UP}

Constant Conductance Heat Pipes 
Each heat pipe condenser was mounted to a common chill block. Each evaporator was mounted to individually controlled heating blocks. Delrin blocks were utilized to provide thermal isolation and structural support to the test set-up. The entire set-up was rigidly mounted to an aluminum frame to provide support during handling and leveling. Due to the orientation of the heat pipe flanges, heat input and output was on a vertical plane. See Figure 1 and 2 . All interfaces utilized chotherm to increase the thermal conductance at the respective joint. MLI was used to help minimize parasitics to the heat pipes from the chamber environment. The flight MLI blankets were used for
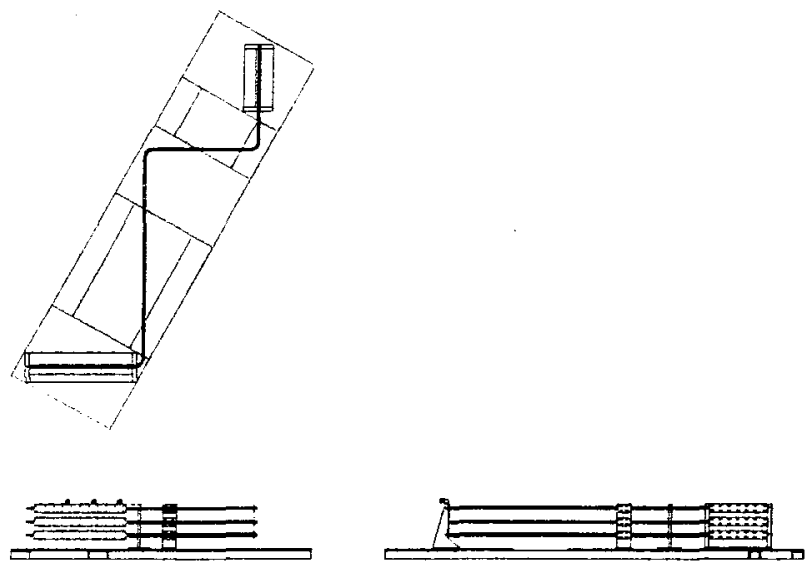

Figure 1. XRT Heat Pipe Test Set-Up Schematic this test without the inner kevlar laver and without the outer silver teflon layer. The evaporator was shimmed accordingly to provide the proper elevations as indicated in the test matrix. The fixture was also capable of orienting the heat pipes such that the condenser end was vertical. Test data in this orientation provided performance of the heat pipes while they were in the "boiler mode" as seen in Figure 3. The NCG test was performed at a 0.28 inch favorable tilt. The heat pipe condenser interface length with the chill block was reduced from $400 \mathrm{~mm}$ to $100 \mathrm{~mm}(15.75$ inch to 4.0 inch) to aid in interpreting the NCG test data.

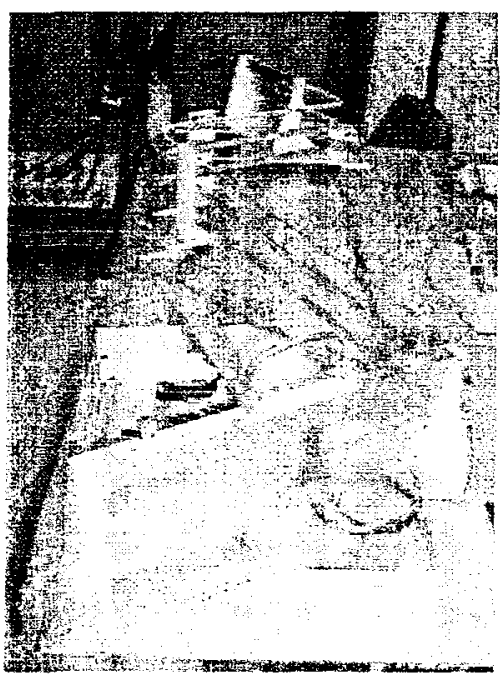

Figure 2. XRT Heat Pipe Test Fixture

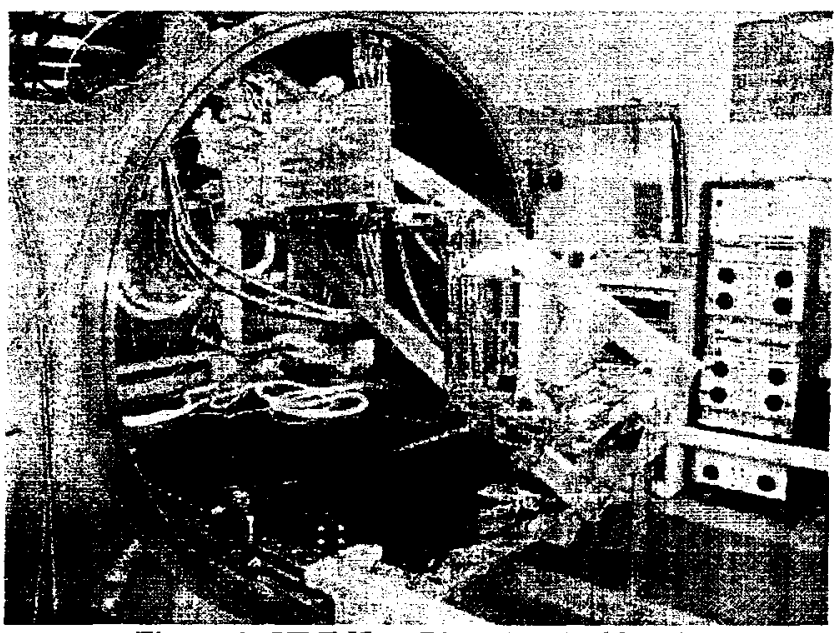

Figure 3. XRT Heat Pipe. Vertical Mode

The entire heat pipe test set up was instrumented with a total of one hundred type $T$ thermocouples. Typical heat pipe thermocouple locations can be seen in Figure t.
The predicted performance for heat pipe transport capability based on shadow graph of actual extrusion, can be seen in Figure 5. (Courtesy of Swales Aerospace). 


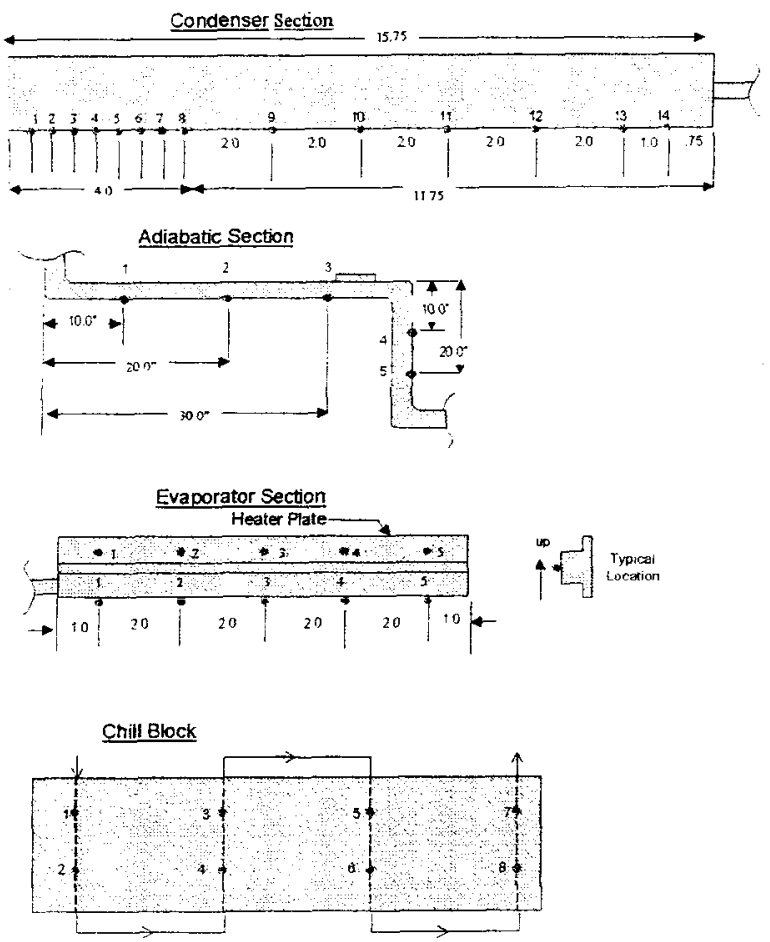

Figure 4. Thermocouple Locations

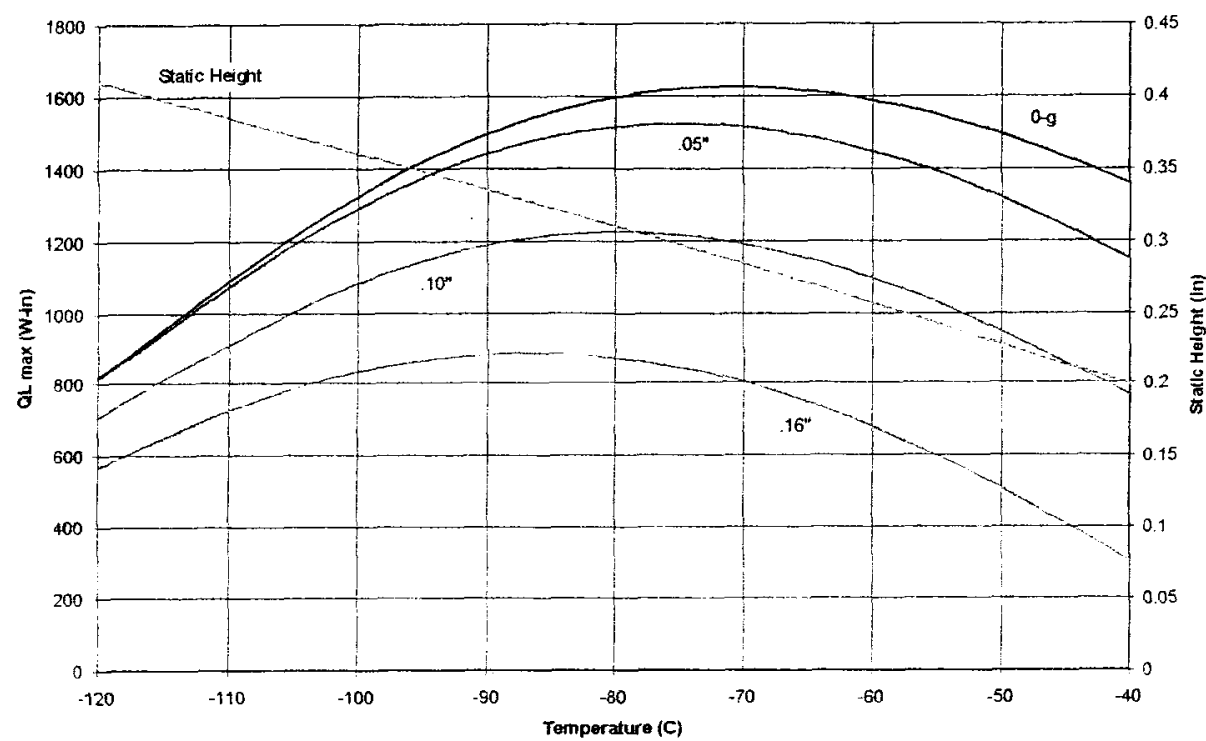

Figure 5. Ethane Transport and Static Height at Various Adverse Tilts Extrusion 9678-12, Box 349 (1-sided heat input)

\section{Heat Rejection System}

The radiator was supported by the titanium flexures to a rigid aluminum frame. which was also designed to support the radiator thermal target. An aluminum channel test fixture supports the FPCA mass simulator. Both of these structures were interconnected and then rigidly mounted to the chamber cart. All of the necessary thermo-mechanical compliance was designed into the flight flexure mounting system. A schematic of the test set-up is shown in Figure 6 . In order to accurately simulate the actual space flight environment. the eleven thermal zones were developed as shown in Table 1. 

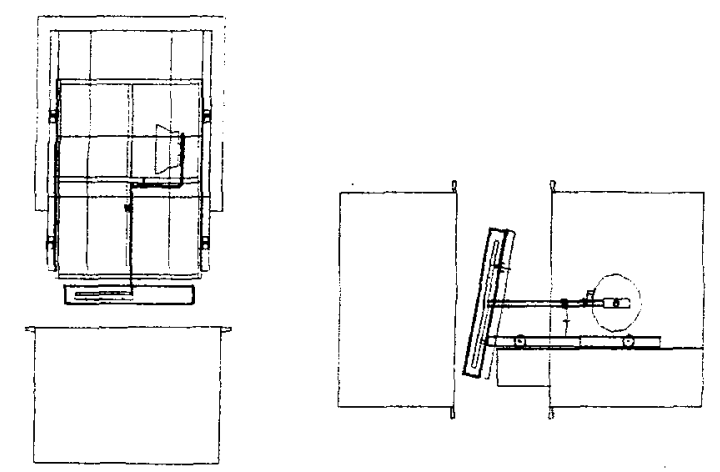

Figure 6. XRT HRS Test Set-Up Schematic in 72 inch Chamber

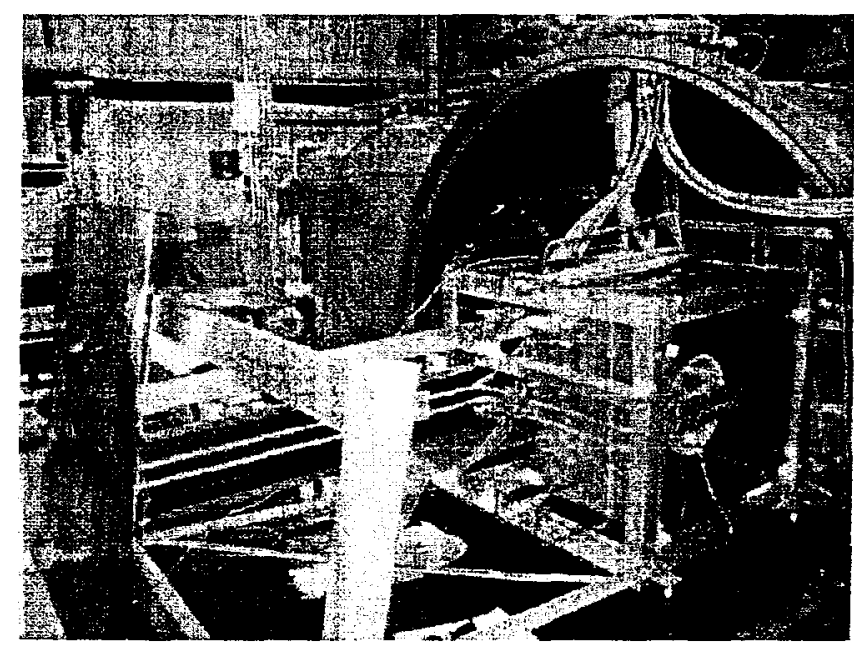

Figure 7. XRT HRS Preliminary Test Set-Up

Table 1. Thermal Environmental Zones

\begin{tabular}{|c|c|c|c|}
\hline Zone & Service & Purpose & Control \\
\hline Zone 1 & $\mathrm{LN}_{2}$ \& Heaters & FPCA 4 sided box & Labview Transient \\
\hline Zone 2 & $\mathrm{LN}_{2}$ \& Heaters & Evaporator, flat plate & Labview Transient \\
\hline Zone 3 & $\mathrm{LN}_{2}$ \& Heaters & Adiabatic 1 & Labview Steady state \\
\hline Zone 4 & $\mathrm{LN}_{2}$ \& Heaters & Adiabatic 2 & Labview Transient \\
\hline Zone 5 & $\mathrm{LN}_{2}$ \& Heaters & Radiator Sink & Labview Transient \\
\hline Zone 6 & Heaters & TEC simulator & UL control \\
\hline Zone 7 & Heaters & Radiator fixture & Omega Steady state \\
\hline Zone 8 & Heaters & Flexure blade & Omega Steady state \\
\hline Zone 9 & Heaters & FPCA housing & Omega Steady state \\
\hline Zone 10 & Heaters & Radiator Bakeout & Omega Steady state \\
\hline Zone 11A \& B & Heaters & Zero Q FPCA casing & Omega Steady state \\
\hline
\end{tabular}

The HRS thermal balance test was instrumented with one hundred and thirty (130), 30 gage type $T$ thermocouples. The FPCA thermal simulator utilized two thermisters. provided by University of Leicester (UL GSE). to measure and record the cold finger temperature. Only test heaters were required for controlling the temperature zones. Test heaters installed on the radiator remain in place and ready for use in subsequent spacecraft level testing when necessary. The test heater utilized for the FPCA thermal simulator was monitored and the power recorded by UL GSE and GSFC GSE. This heater was made up of two separate circuits for redundancy. They are referred to as circuit \#1 and circuit \#2 and were operated by UL GSE. 


\section{TEST PROGRAM}

\section{Constant Conductance Heat Pipes}

The objectives of this test program were to qualify the heat pipes as required by the specification. The acceptance criteria included: 1) The zero gravity heat transport capacity of the CCHP's shall be at least 1300 watt-inch at $-40^{\circ} \mathrm{C}$. This is an extrapolated value based on the results from the three different adverse tilt configurations. 2) Each CCHP shall demonstrate an evaporator conductance of at least $0.5 \mathrm{~W} / \mathrm{K}$-inch and a condenser conductance of at least $0.7 \mathrm{~W} / \mathrm{K}$-inch. This is calculated based on a $75 \%$ of maximum heat load at $40^{\circ} \mathrm{C}$. 3) For non condensable gas (NCG) test, a gradient across the condenser shall be less than $1.0^{\circ} \mathrm{C}$ for a 5 watt heat input at $-95^{\circ} \mathrm{C}$ while at 0.25 inch reflux favorable tilt. 4) A calibrated residual gas analyzer (RGA) shall be attached to the thermal vacuum chamber to monitor the presence of ethane within the chamber throughout the test program. No detectable ethane molecules shall be detected by the RGA during the initial hot soak at $35^{\circ} \mathrm{C}$.

\section{Heat Rejection System}

The objectives of this test program were to validate the HRS under a wide range of environmental conditions. The overall requirement is for the HRS to maintain the cheater plate at or below $-42^{\circ} \mathrm{C}$ under worst hot case conditions and a TEC power dissipation curve passing through 10 watts at $-38^{\circ} \mathrm{C}$. The $4^{\circ} \mathrm{C}$ temperature difference was designed to account for $1^{\circ} \mathrm{C}$ conductance loss and $3^{\circ} \mathrm{C}$ degrees of margin. The cold finger/proton shield thermal simulator (FPCA simulator) is designed to simulate the waste heat from the hot side of the flight TEC. The TEC power versus temperature curve has been provided by the UL which represents an unloaded TEC operational output power. A scaling factor is used that increases the power dissipation to 10 watts at $40^{\circ} \mathrm{C}$. The simulator control is achieved by a Labview controlled heater system providing a Proton Shield temperature regulated power output. A thermal incident gain test was performed to quantify the heat leak from the FPCA simulator to the external casing for calibration purposes.

\section{TEST RESULTS}

\section{Constant Conductance Heat Pipes}

Table 2 includes the results obtained for all of the heat transport tests at all elevations. The zero gravity heat transport capacity is extrapolated from the chart as seen in Figure 8 using polynomial fitting, and is above 1300 $\mathrm{W}$-inch. Heat pipe $\mathrm{S} / \mathrm{N} 002$ is not displayed on this chart since it is nearly identical to heat pipe $\mathrm{S} / \mathrm{N} 003$.

Thermal conductance values were calculated based on $75 \%$ of the maximum heat load during the $40^{\circ} \mathrm{C}$ heat transport test at 0.05 inch tilt and can be seen in Table 3.

The NCG test was performed at 0.280 inch reflux mode tilt configuration. An evaporator heat load of 3 , 5 , and 7 watts were applied at a heat pipe condenser temperatures of $-95^{\circ} \mathrm{C}$ and at $-120^{\circ} \mathrm{C}$. There was no indication of NDG based on the temperature data throughout these tests.

Table 2. XRT Heat Pipe Transport Limit

\begin{tabular}{|c|l|l|l|l|l|l|l|l|l|l|l|}
\hline & \multicolumn{9}{c|}{ Adverse Tilt Elevation } & \multicolumn{3}{c|}{$\begin{array}{l}\text { Vertical } \\
\text { Mode }\end{array}$} \\
\hline & \multicolumn{3}{|c|}{0.15 inch } & \multicolumn{3}{c|}{0.1 inch } & $-40 \mathrm{C}$ \\
\hline $\begin{array}{c}\text { Heat } \\
\text { Pipe }\end{array}$ & $-40 \mathrm{C}$ & $-70 \mathrm{C}$ & $-120 \mathrm{C}$ & $-40 \mathrm{C}$ & $-70 \mathrm{C}$ & $-120 \mathrm{C}$ & $-40 \mathrm{C}$ & $-70 \mathrm{C}$ & $-120 \mathrm{C}$ & $\begin{array}{l}-70 \mathrm{C} \text { to }- \\
120 \mathrm{C}\end{array}$ \\
\hline 2 & 16 watts & 15 watts & 8 watts & 13 watts & 13 watts & 7 watts & 8 watts & 8.5 watts & 4 watts & $>15$ watts \\
\hline 3 & 17 watts & 15 watts & 8 watts & 13 watts & 13 watts & 6 watts & 8 watts & 8.5 watts & 5 watts & $>15$ watts \\
\hline 4 & 18 watts & 14 watts & 7 watts & 15 watts & 15 watts & 6 watts & $\begin{array}{l}10 \\
\text { watts }\end{array}$ & 9.5 watts & 5 watts & $>15$ watts \\
\hline
\end{tabular}




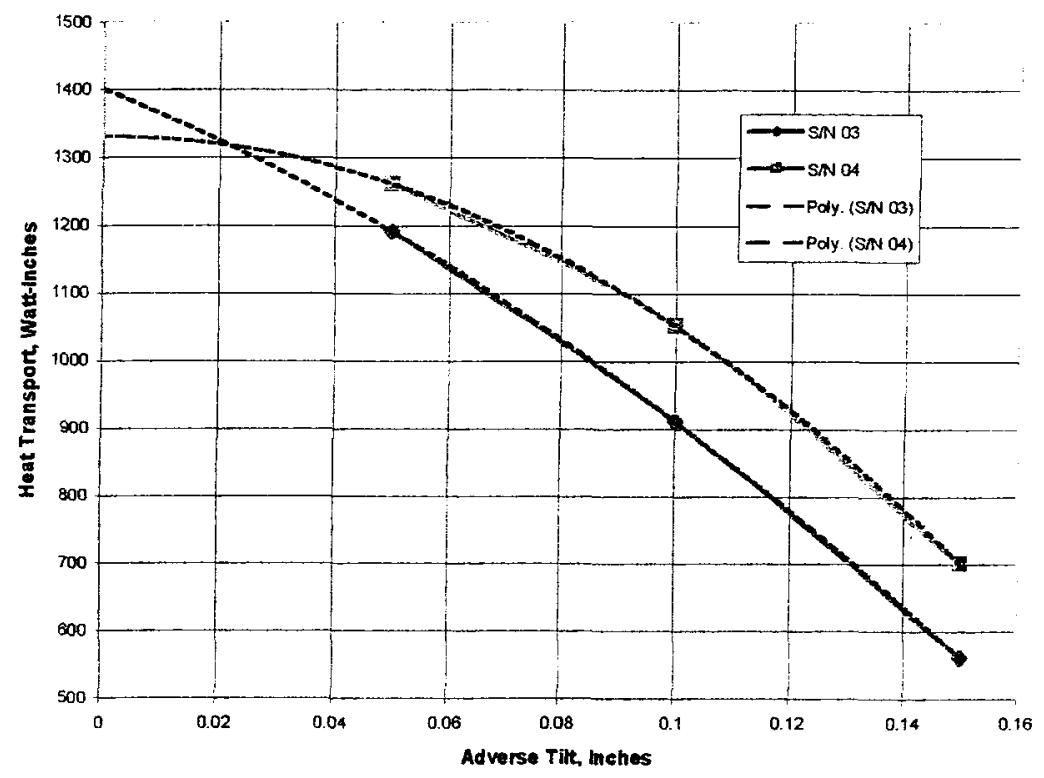

Figure 8. XRT Heat Pipe Heat Transport Test Data at $-40^{\circ} \mathrm{C}$

Table 3. Calculated Heat Pipe Conductance Values at $-40^{\circ} \mathrm{C}$ and 0.05 inch tilt

\begin{tabular}{|c|c|c|}
\hline Heat Pipe Designation & $\begin{array}{c}\text { Evaporator Conductance } \\
\text { W/K-inch }\end{array}$ & $\begin{array}{c}\text { Condenser Conductance } \\
\text { W/K-inch }\end{array}$ \\
\hline S/N 002 & 0.6 & 1.2 \\
\hline S/N 003 & 1.1 & 1.7 \\
\hline S/N 004 & 1.2 & 3.5 \\
\hline
\end{tabular}

In order to gain an understanding of the heat pipe performance during spacecraft level thermal vacuum testing, a vertical mode test was performed. The evaporator is at the lowest elevation and the condenser is above it. This is also referred to as gravity assist or reflux mode. For the XRT ethane heat pipes, the evaporator is actually horizontal and the condenser is vertical with a slight downward $(0.180 \mathrm{inch})$ tilt in the horizontal adiabatic section to ensure proper fluid drainage. During these tests, the heat pipes were operated at $-40^{\circ} \mathrm{C},-70^{\circ} \mathrm{C}$ and $-120^{\circ} \mathrm{C}$. The power to each heat pipe was initially set to 3 watts and then increased in three watt increments up to 15 watts with no sign of dry out. The temperature of each evaporator oscillated during the $-120^{\circ} \mathrm{C}$ case as the fluid was evaporating (superheating) and then re-condensed. The period of oscillation decreased with increasing power. This verified that the heat pipes will operate in reflux mode at the spacecraft level test. The evaporator temperature never exceed the limit of $-40^{\circ} \mathrm{C}$.

The RGA was used during the test to certify that all three ethane heat pipes are leak tight at all test temperatures. A hot survival soak was performed at $35^{\circ} \mathrm{C}$ to ensure integrity at this temperature. No ethane leaks were detected throughout the test program.

\section{Heat Rejection System}

The overall performance of the HRS system was acceptable for all test cases. See Table 4 for the test case boundary conditions, measured powers and operating temperatures. Zone 1 heater controller failed after case 1 so orbital averages were subsequently used instead of the transients. This zone had large temperature gradients, which were reduced when orbital averages were implemented. Also, one of the zone 6 heaters failed requiring circuit \#2 to be used $100 \%$ for the remainder of the test, thus not allowing a $50 / 50$ split of heater power which would have reduced the gradient across the simulator. Case $1 \mathrm{~A}$ was nun to further demonstrate the robustness of the system with a fixed heater load for the simulator. 
Table 4. XRT HRS Environmental Zone Test Cases and Test Values

\begin{tabular}{|c|c|c|c|c|c|c|}
\hline & & Case 1 & Case $1 \mathrm{~A}$ & Case 2 & Case 3 & Case 4 \\
\hline Zone & Purpose & $\begin{array}{c}\text { Worst Hot } \\
\text { Orbit } \\
\text { Transient } \\
\text { Operating }\end{array}$ & $\begin{array}{c}\text { Worst Hot } \\
\text { Orbit } \\
\text { Transient } \\
\text { Operating }\end{array}$ & $\begin{array}{l}\text { Worst Hot in } \\
\text { Sunlight to } \\
\text { Worst Cold in } \\
\text { Eclipse } \\
\text { Transient } \\
\text { Operating }\end{array}$ & $\begin{array}{c}\text { Worst Cold } \\
\text { Orbit } \\
\text { Transient } \\
\text { Operating }\end{array}$ & $\begin{array}{c}\text { Worst Cold } \\
\text { Orbit Transient } \\
\text { Non-Operating }\end{array}$ \\
\hline Zone 1 & FPCA, four sided box & Transient & -13 & -31 & -76 & -76 \\
\hline Zone 2 & Evaporator, ffat plate & Transient & Transient & Transient & Transient & Transient \\
\hline Zone 3 & short (vertical) doghouse & Transient & Transient & Transient & Transient & Transient \\
\hline Zone 4 & long (horiz.) doghouse & 40 & 40 & 40 & -25 & -35 \\
\hline Zone 5 & Radiator Sink & Transient & Transient & Transient & Transient & Transient \\
\hline Zone 6 & TEC simulator & Auto & Manual & Auto & Auto & OFF \\
\hline Zone 7 & Radiator fixture & 40 & 40 & 40 & -25 & -35 \\
\hline Zone 8 & Flexure blade & 10 & 10 & 10 & 10 & 10 \\
\hline Zone 9 & FPCA casing & 30 & 30 & 30 & 20 & 0 \\
\hline Zone 10 & Radiator Bakeout & $\mathrm{n} / \mathrm{a}$ & $\mathrm{n} / \mathrm{a}$ & $\mathrm{n} / \mathrm{a}$ & $\mathrm{n} / \mathrm{a}$ & $n / a$ \\
\hline Z11AVB & FPCA casing zero $Q$ & 30 & 30 & 30 & 20 & 0 \\
\hline \multicolumn{7}{|l|}{$\begin{array}{c}\text { Test } \\
\text { Values }\end{array}$} \\
\hline Zone 9 & Casing s.s power, fluke & 2.95 & 3.24 & 3.85 & 4.35 & 3.15 \\
\hline Zone 6 & TEC max/min power, fluke & not available & 6.99-7.04 & $3.1-4.0$ & $0.9-1.03$ & $n / a$ \\
\hline Zone 6 & TEC max/min power, UL & $6.2-7.5$ & $8.96-8.97$ & $4.0-5.1$ & $1.26-1.38$ & $\mathrm{n} / \mathrm{a}$ \\
\hline Zone 6 & Cold finger pk-pk, TC 56 & $-45 /-50$ & $-49 /-53$ & $-59 /-64$ & $-90 /-93$ & $-93 /-97$ \\
\hline Zone 6 & Cold finger $p k-p k, U L$ avg & $-43 /-47$ & $-47 /-52$ & $-56 /-62$ & $-86 /-89$ & $-90 /-94$ \\
\hline Zone 6 & Scaled look up table & $9 w /-40$ & 9 w fixed & $10 w /-40$ & $10 w /-40$ & $\mathrm{n} / \mathrm{a}$ \\
\hline Zone 6 & Active heaters & $\# 1100 \%$ & \#2 100\% & $\# 2100 \%$ & $\# 2100 \%$ & $\mathrm{n} / \mathrm{a}$ \\
\hline
\end{tabular}

\section{Constant Conductance Heat Pipe's}

All three heat pipes passed the acceptance test criteria. $\mathrm{S} / \mathrm{N} 003$ and $\mathrm{S} / \mathrm{N}-004$ were selected as the flight pipes based on the calculated conductance values. These two pipes will be included in the XRT HRS test program and $\mathrm{S} / \mathrm{N} 002$ will become a flight spare.

During the initial testing of the heat pipes at $0.100 \mathrm{inch}$ adverse tilt, one of the heat pipes was performing poorly with respect to the other two. A chamber break was performed and it was noticed that the ill performing heat pipe had a 0.030 valley in its adiabatic section. This small discrepancy in relative height is enough to slew test data when working with low surface tension fluids such as ethane. Once the proper level of the adiabatic section was corrected. the heat pipe performed as expected.

Although not expected to operate as "heat pipes" in the ambient temperature range. we were pleasantly surprised when they did. When the condenser temperature was set to $33^{\circ} \mathrm{C}$ during the initial bakeout. the heat pipes were isothermal during this transition. There was no need to apply heat to the evaporators. Subsequent tests required warming the heat pipes to ambient prior to breaking vacuum. Six watts were applied to the evaporators and all heat pipes warmed isothermally to $22^{\circ} \mathrm{C}$. Note: The critical temperature of ethane is $32^{\circ} \mathrm{C}$, above this temperature it becomes supercritical and will no longer behave like a heat pipe. Above this critical temperature. the internal pressure can be calculated as an ideal gas ( $\mathrm{PV}=\mathrm{nRT}$ ). At $32^{\circ} \mathrm{C}$, the internal pressure for ethane is $4.98 \mathrm{MPa}$ ( $723 \mathrm{psia}$ ).

\section{Heat Rejection Svstem}

The XRT HRS performed well within the margins for all of the test cases. The temperature of the thermal simulator never exceeded $-42^{\circ} \mathrm{C}$ during the worst hot case while dissipating a worst case, 9 watts continuous heat load (test case 1A). The heat path between the FPCA casing and the thermal simulator could have been better thermally isolated as noted during the thermal incident gain test. 
During the post test evaluation, the heat leak through the instrumentation hamess was calculated to be about 0.5 watt. The heat leak was further realized as the sensitivity of the thermal simulator relative to the temperature of the FPCA casing was demonstrated. A small change in the controlled temperature of the FPCA casing was noticed as a small change in the temperature of the cold finger. However, since the amount of power related to the heat leak from the casing was measured, it can be factored into the test results. The temperature of the thermal simulator reached $-92^{\circ} \mathrm{C}$ during the worst cold case and may be even colder with a reduced heat leak from the flight FPCA and reduced heat load from a more efficient TEC. These effects on the XRT instrument are being analyzed. The overall results can be seen graphically in Figure 9

\section{Conclusion}

All three heat pipes satisfied the zero gravity heat transport minimum requirement of 1300 watt-inches (33 watt meters) at $-40 \mathrm{C}$. Non condensable gas tests were successfully completed with no indications of NCG. Oscillatory temperature behavior at the evaporator end was observed at the lower temperature extremes during the vertical mode. This could possibly limit the instrument operating temperature range at spacecraft level ground testing.

The cold case test results demonstrated that the HRS might be "too" efficient as the evaporators approached the control point of the TEC $\left(-105^{\circ} \mathrm{C}\right)$.

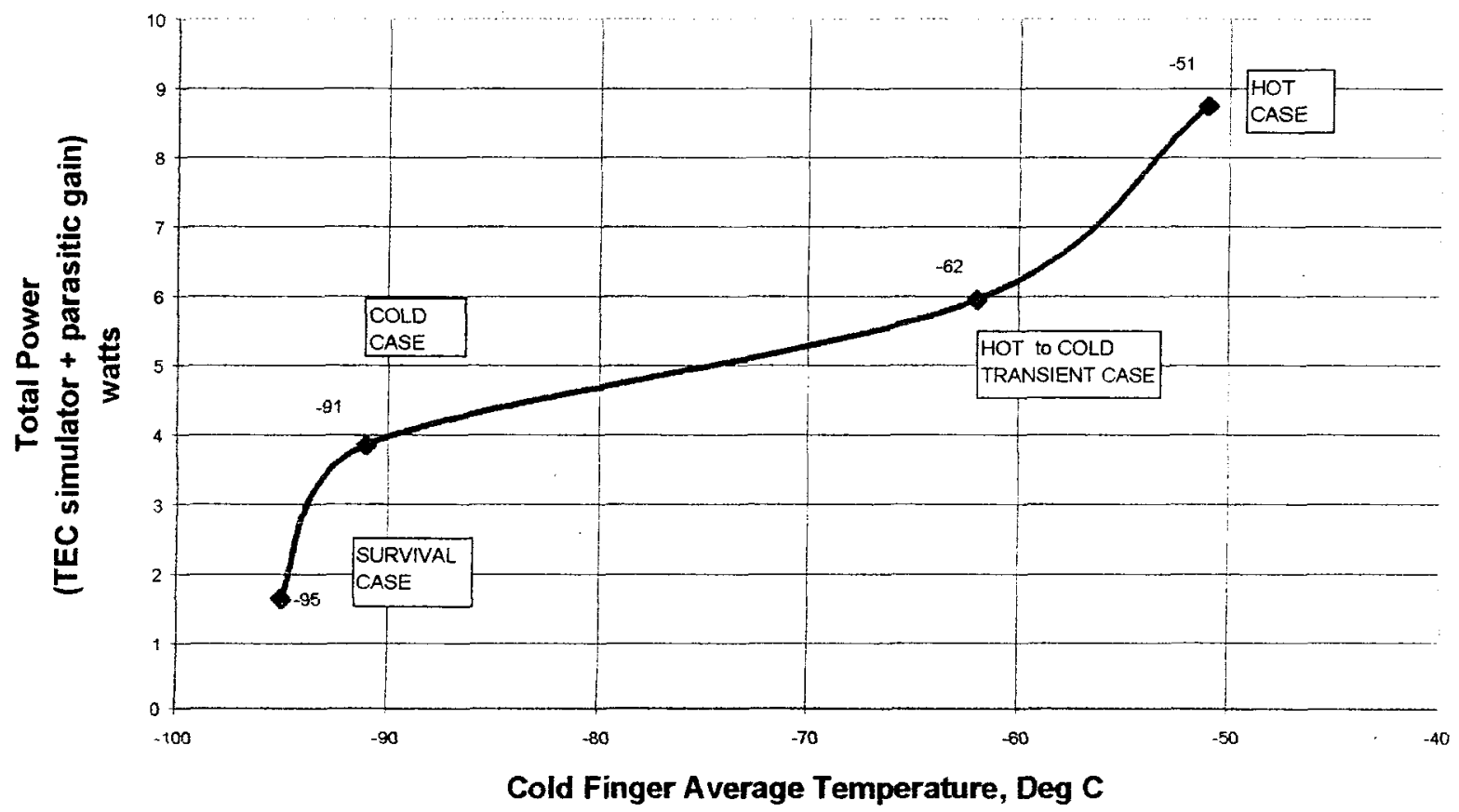

Figure 9. Cold Finger Temperature vs Power as a function of test case boundary conditions

\section{REFERENCES}

1. Choi. M. K., "Thermal Considerations of Swift XRT Radiator at $-35{ }^{\circ} \mathrm{C}$ of Colder in Low Earth Orbit." Paper No. AIAA-2000-2906. IECEC 2000. Las Vegas. NV. July 2t-28. 2000.
2. McIntosh, R., McCreight, R.C., and P.J. Brennan, "Long Duration Exposure Facility (LDEF) Low Temperature Heat Pipe Experiment Package (HEPP) Flight Results," Report No. N93-29701, NASA. Langley, VA. 1993. 